\title{
The evolutionary characteristics of the network attention of the five tourism performing arts products on the time scale
}

\author{
Li Guanghong ${ }^{1}$, Zhang Yulin ${ }^{1}$ \\ ${ }^{1}$ College of Tourism and Landscape Architecture, Guilin University of Technology, Guilin Guangxi 541000, China
}

\begin{abstract}
Network attention is the intuitive expression of tourism demand and behavior habits on the Internet, with the help of Baidu Index platform to obtain the online attention of the five major tourism performing arts products from 2015 to 2019 , and use quantitative methods to analyze their annual, monthly and weekly changes. The results are as follows, from the perspective of interannual change, the network attention of "Ancient Love of Song City" and "Amazing Xiangxi" shows an upward trend, while the rest of the impression series products show negative growth; from the perspective of monthly change, the network attention of "Impression Liu Sanjie", "Ancient Love of Song City" and "Impression West Lake" has seasonal characteristics; the overall change trend is mainly affected by the National Day holiday and summer vacation, the curve trend of "Impression Lijiang" and "Amazing Xiangxi" is relatively stable; from the weekly change, the weekly change of tourism performing arts products is very small.
\end{abstract}

\section{Introducion}

In the era of information society, as of March 2020, the number of Chinese netizens has exceeded 900 million, and the Internet has become the preferred platform for tourists to choose tourism destinations. Tourists obtain tourism information through the Internet, which provides a basis for destination selection, tourism activities arrangement and so on. At present, the traditional data sources have lagged behind the rapid development of tourism, the use of the Internet to obtain data has become a hot spot, Baidu Index is an important tool to study network attention. Many scholars use Baidu index to analyze the tourists' attention of a certain tourism destination, and the research content is mainly focused on the temporal and spatial characteristics of network attention, He Xiaoqian et al. and Du Mengyi et al. respectively studied the temporal and spatial characteristics of network attention of different types of tourism activities ${ }^{12}$. Xu Fan et al. and Huang Wensheng mainly focus on different provinces or regions ${ }^{[3][4]}$. The relationship between online attention and tourist volume is also a hot topic studied by scholars. Long Maoxing analyzed the correlation between tourism network attention and actual tourist flow in Sichuan Province 5 . Sun Ye et al. analyzed and compared the prediction results and ability of Baidu index of different clients on tourist volume ${ }^{6}$. To sum up, Baidu index has become an important tool to study tourism network attention, and the analysis of the temporal and spatial characteristics of network attention is one of the research hotspots.

Tourism performing arts is the best carrier for the combination of culture and tourism industry, which combines local cultural and natural resources and spreads local resource endowments and cultural customs to tourists through exhibition activities in tourist destinations. Domestic scholars have done a lot of research on tourism performing arts, but mainly qualitative research is too much, quantitative research is relatively lack, the research results are one-sided. In view of this, this paper takes the five well-known tourism performing arts products as the research object, takes the Baidu index as the data source, and analyzes the changing characteristics of the attention of tourism performing arts products from the time dimension, in order to promote the sustainable development of tourism performing arts industry.

\section{Data sources and research methods}

\subsection{Data sources}

The search volume of "Impression Lijiang", "Impression Liu Sanjie", "Impression West Lake", "Ancient Love of Song City" and "Amazing Xiangxi" ranked top 5 by using Aizhan website to query related tourism performing arts products. Therefore, this paper uses these five nouns as retrieval keywords to count the Baidu index data from January 1, 2015 to December 31, 2019. The retrieved data obtained is called "network attention", which reflects actual or potential travel The degree of interest and time changes of the visitors to tourism performing arts products on the Internet.

\footnotetext{
${ }^{1}$ Corresponding author:1615673704@qq.com
} 


\subsection{Research methods}

The Baidu index is used to retrieve the overall national attention data of five keywords, and the annual, monthly and weekly variation curves of network attention from 2015 to 2019, and conduct data statistics and comparative analysis. The coefficient of variation is used to calculate the monthly difference of online attention of tourism performing arts products. The formula is as follows.

$$
C_{v}=\frac{1}{\bar{y}} \sqrt{\sum_{i=1}^{n}\left(y_{i}-\bar{y}\right)^{2} / n}
$$

In the formula, $C_{v}$ is the coefficient of variation, $y_{i}$ is the attention degree of the $i$ th month; $\bar{y}$ is the average value of $y_{i}$.The greater the coefficient of variation, the greater the degree of monthly variation in the degree of network attention.

\section{3 general situation of the object of study}

The large-scale landscape performance "Impression Liu Sanjie" launched in 2004 is an example of the successful operation of the domestic cultural industry, which has triggered an upsurge in the development of domestic large-scale live performances and tourism performing arts industry. "Ancient Love of Song City" is currently the most frequently performed performance in the theatre in the world. "Impression Lijiang" and "Impression West Lake" show the audience a high-level landscape performance, and "Amazing Xiangxi" has created a gold-lettered signboard of Zhangjiajie cultural and tourism industry. These five major tourism performing arts products respectively take the display and dissemination of local characteristics as their own responsibility, and they are representative works for the prosperity and development of the tourism performing arts industry. Therefore, this paper takes the network attention of these five major tourism performing arts products as the research object, and analyzes the change characteristics of the time dimension from 2015 to 2019.

\section{4 the characteristics of time evolution of network attention}

\subsection{Annual variance}

By searching the overall search index of the five major tourism performing arts products and statistical values, the annual online attention from 2015 to 2019 is obtained (figure 1). As shown in figure 1, the overall annual data of the online attention of the five major tourism performing arts products can be divided into two categories. The first is the curve of the growth trend, such as "Ancient Love of Song City" and "Amazing Xiangxi". Among them, the curve of "Ancient Love of Song City" rises more greatly, indicating that its rich cultural connotation and vivid performance form have been loved by the public. The second type is the curve of negative growth trend, which is mainly represented by the downward trend of network attention of the three major products in the impression series. By comparing the five annual curves, it can be found that the network attention of "Ancient Love of Song City" has been dominant, fluctuating slightly in 2018, but in a state of steady growth as a whole. Although the online attention of "Amazing Xiangxi" shows a steady rise, it is lower than that of other products in the past five years, indicating that the tourism attraction of "Amazing Xiangxi" is not high, but it has great potential for development. The change range of "Impression Liu Sanjie" is similar to that of "Impression West Lake", but the overall value of "Impression West Lake" is always lower than that of "Impression Liu Sanjie". "Impression Lijiang" showed a decline in the first 4 years and an upward trend in 2019. Although the attention of impression series is declining obviously, it still occupies a large market share and makes a great contribution to China's tourism and performing arts market.

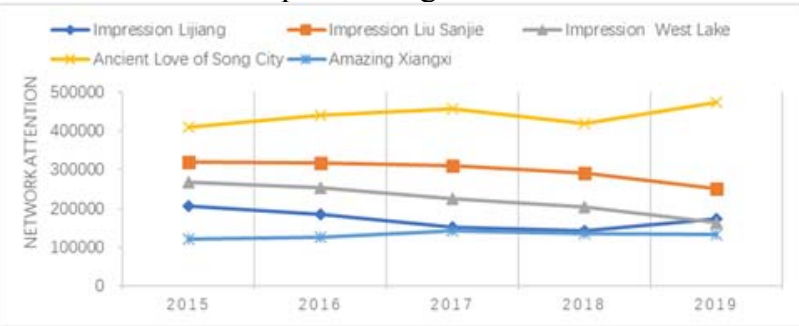

Figure 1. the annual changes of online attention of the five major tourism performing arts brands from 2015 to 2019

\subsection{Monthly variance}

The Baidu index is used to obtain the online attention of the five major tourism performing arts products from January to December from 2015 to 2019 and calculate their monthly average, as shown in figure 2 . The monthly change curve of the network attention degree of "Impression Liu Sanjie" and "Ancient Love of Song City" shows "M" shape, and "Impression West Lake" shows obvious inverted "V" shape. The attention degree of these three major tourism performing arts products has significant seasonal characteristics. The monthly difference between "Impression Lijiang" and "Amazing Xiangxi" is relatively small, and the curve trend is relatively stable. The attention of these five products accelerated from July to August, and the summer vacation was the hot period for the tourism performing arts products network. January and December were the troughs of the year, due to the influence of cold climatic conditions. People's choice of this kind of live performance is limited. Stimulated by the National Day holiday, October is another hot period of online attention of "Impression Liu Sanjie" and "Ancient Love of Song City". Compared with other holidays, the National Day holiday has a greater pulling effect on the network attention of tourism performing arts products. 


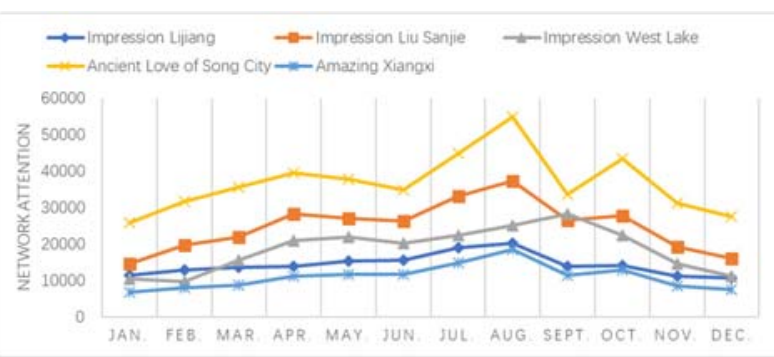

Figure 2. monthly changes in online attention of the five major tourism performing arts brands from 2015 to 2019

Using the coefficient of variation to compare the discretization of the monthly average attention of the five major tourism performing arts products in 2015-2019 (Table 1), the greater the coefficient of variation, the greater the degree of discretization of the data, the smaller the coefficient of variation, the smaller the degree of discretization of the data. As can be seen from Table 1, all the coefficients of variation are less than 1 , but they are relatively high, indicating that the network attention of potential tourists has an obvious off-peak season in one year. Among them, under the influence of the G20 summit in Hangzhou in September 2016, the online attention of "Impression West Lake" fluctuated greatly, with a coefficient of variation as high as 0.6489 . The coefficients of variation of "Impression Lijiang", "Impression West Lake" and "Amazing Xiangxi" show fluctuating upward trends, while "Impression Liu Sanjie" and "Ancient Love of Song City" show fluctuating downward trends.

Table1. Coefficient of variation of monthly average online attention from 2015 to 2019

\begin{tabular}{cccccc}
\hline products & \multicolumn{5}{c}{ Coefficient of Variation } \\
& 2015 & 2016 & 2017 & 2018 & 2019 \\
\hline $\begin{array}{c}\text { Impression } \\
\text { Lijiang }\end{array}$ & 0.2451 & 0.1681 & 0.1680 & 0.1603 & 0.2711 \\
$\begin{array}{c}\text { Impression } \\
\text { Liu Sanjie }\end{array}$ & 0.3517 & 0.3040 & 0.2085 & 0.2512 & 0.2611 \\
$\begin{array}{c}\text { Impression } \\
\text { West Lake } \\
\text { Ancient }\end{array}$ & 0.3316 & 0.6489 & 0.2761 & 0.2976 & 0.3357 \\
$\begin{array}{c}\text { Love of } \\
\text { Song City } \\
\text { Amazing }\end{array}$ & 0.2539 & 0.1556 & 0.2037 & 0.2967 & 0.2444 \\
Xiangxi & 0.3118 & 0.2839 & 0.2857 & 0.3066 & 0.3592 \\
\hline
\end{tabular}

\subsection{Weekly difference}

The data of these five major tourism performing arts products from January 1, 2015 to December 31, 2019 can be retrieved on the Baidu Index, and the weekly average of online attention from 2015 to 2019 is calculated by intercepting the weekly attention values of each year from Monday to Sunday. The weekly average change of each year is used as the standard to study the weekly difference. In order to facilitate the calculation and analysis of the week of attention, the weeks of each year are divided into 51 weeks from January 5 to December 27 in 2015, 51 weeks from January 4 to December 25 in 2016, 52 weeks from January 2 to December 31 in 2017, 52 weeks from January 1 to December 30 in 2018, and 51 weeks from January 7 to December 29 in 2019.

As shown in figure 3 , the online attention curve from Monday to Sunday has developed horizontally over the past five years, and the distribution is similar to a horizontal straight line, indicating that the weekly change of tourism performing arts products is small and is almost not affected by weekdays or weekends.

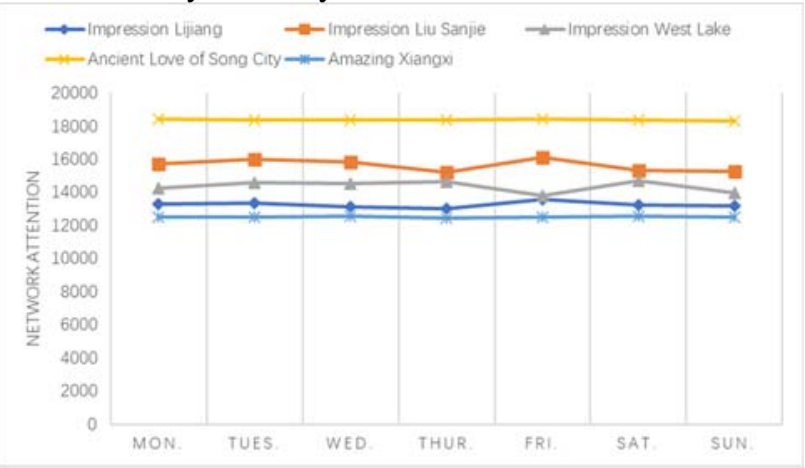

Figure 3. changes of online attention week of five major tourism performing arts brands from 2015 to 2019

\section{Conclusion}

In this paper, the Baidu index is used to analyze the time evolution characteristics of the five most popular tourism performing arts products. The main conclusions are as follows: from the perspective of interannual change, the network attention of "Ancient Love of Song City" has always been in the first place. And it is in a state of improvement with "Amazing Xiangxi", and the network attention of the three products of the impression series is in a negative growth trend. From the perspective of monthly change, the monthly change curve of the network attention degree of "impression Liu Sanjie" and "Ancient Love of Song City" shows "M" shape, and "Impression West Lake" shows obvious inverted "V" shape. The attention of these three major tourism performing arts products has seasonal characteristics, the monthly difference between "Impression Lijiang" and"Amazing Xiangxi" is relatively small, and the overall change trend is basically consistent with the National Day holiday and summer vacation time. From the perspective of weekly changes, the weekly changes of tourism performing arts products are very small, and weekdays or weekends have little impact on their attention.

\section{References}

1. He Xiaoxing, Zhang Yanrong, Liu Yu. A study on the Spatio-temporal characteristics of tourist Cave Network attention-- A case study of the five most beautiful tourist caves in China [J]. Karst in China, 2017. 36 (02): 275-282.

2. Du Mengyi, Yang Xiaoxia, Chen Peng. Research on Spatio-temporal characteristics of Network attention in online Celebrity Scenic spots based on Baidu Index-- A case study of Hongya Cave in Chongqing [J]. Journal of Southwest normal University (Natural Science Edition), 2020545 (06): 72-79.

3. Xu Fan, you Wei, Anniversary Xing, Hu Meijuan. Research on Spatio-temporal Distribution of attention in Cyberspace based on Baidu Index-- A case study of 
5A Scenic spot in Yangtze River Delta [J]. Resource Development and Market, 2016 pr 32 (04): 489-493.

4. Huang Wensheng. Research on Guangxi Tourism Network attention rate Matrix and Marketing Strategy based on Baidu Index [J]. Regional Research and Development, 20195138 (05): 101104.

5. Long Maoxing, Sun Gennian, Ma Lijun, Wang Jiejie. Comparative Analysis of Spatio-temporal Dynamics of Regional Tourism Network attention and passenger flow-- A case study of Sichuan [J]. Regional Research and Development, 2011 Magi 30 (03): 93-97.

6. Sun Ye, Zhang Honglei, Liu Peixue, Zhang Jie. A study on the Prediction of Daily tourist Volume in Scenic spots based on the attention of tourists' Network-- taking different client Baidu Index as an example [J]. Human Geography, 2017. 32 (03): 152160. 